\title{
ПОЛИТИКА ЭКОНОМИЧЕСКОЙ БЕЗОПАСНОСТИ КАК НЕОБХОДИМЫЙ ЭЛЕМЕНТ ЭФФЕКТИВНОГО ФУНКЦИОНИРОВАНИЯ СОВРЕМЕННЫХ КОМПАНИЙ
}

\author{
(C) 2021 Дуболазова Юлия Андреевна
}

кандидат экономических наук, доцент Высшей инженерно-экономической школы Санкт-Петербургский политехнический университет Петра Великого, Россия, Санкт-Петербург E-mail: dubolazova_yau@spbstu.ru

(c) 2021 Ячменева Екатерина Дмитриевна

студент, Высшая инженерно-экономическая школа

Санкт-Петербургский политехнический университет Петра Великого, Россия, Санкт-Петербург E-mail: katja-jachmeneva0@mail.ru

Статья посвящена исследованию теоретических и методических вопросов политики экономической безопасности. Цель настоящей публикации заключается в детализации, а также дальнейшей систематизации подходов к разъяснению сущности понятия «политика экономической безопасности современных компаний». В рамках данной статьи обобщены базовые рекомендации, необходимые для формирования эффективной политики экономической безопасности хозяйствующего субъекта.

Ключевые слова: экономическая безопасность, хозяйствующий субъект, политика экономической безопасности, функции, комплекс мероприятий, эффективность, управление, требования, рекомендации.

В настоящее время наличие политики экономической безопасности является скорее нормой нежели исключением для современных предприятий крупного и среднего бизнеса. Вопрос ее совершенствования и развития является достаточно актуальным и обсуждаемым как на уровне теории, так и на уровне практики. Интерес к данной тематике обусловлен рядом причин, основными из которых являются следующие: во-первых, в условиях достаточно ограниченного круга исследований по данному вопросу наблюдается отсутствие системности, скоординированности и единства взглядов относительно категорийно-понятийного аппарата, во-вторых, отсутствуют теоретико-методические основы и обоснованные предложения по внедрению алгоритмов, а также методов и моделей управления экономической безопасностью в целом как на уровне экономики страны, так и на уровне хозяйствующих субъектов.

Интерпретируя сущность политики экономической безопасности на микроуровне, то есть на уровне отдельно взятого предприятия необходимо отталкиваться от родового понятия экономической безопасности как таковой.

Экономическая безопасность предприятия является сложным комплексным понятием, ко- торое характеризует уровень защищенности и независимости предприятия, достигаемое путем формирования эффективной политики развития хозяйствующего субъекта [5].

Схематично сущность экономической безопасности хозяйствующего субъекта может быть представлена в виде рисунка 1.

Политика экономической безопасности выступает принципиально важным структурным элементом системы экономической безопасности компании в целом. Основная задача политики экономической безопасности - сформировать устойчивый механизм развития компании в настоящем и будущем.

В общепринятом понимании политика экономической безопасности хозяйствующего субъекта представляет собой комплекс систематизированных мероприятий, направленных на достижение целей конкретной организации. Примеры таких целей представлены на рисунке 2.

По мнению большинства специалистов в области экономической безопасности, динамичное развитие современной компании зависит не только от выработанной стратегии экономической безопасности, но и от сбалансированной политики ее реализации, достигаемой путем рационального использования ресурсов и воз- 


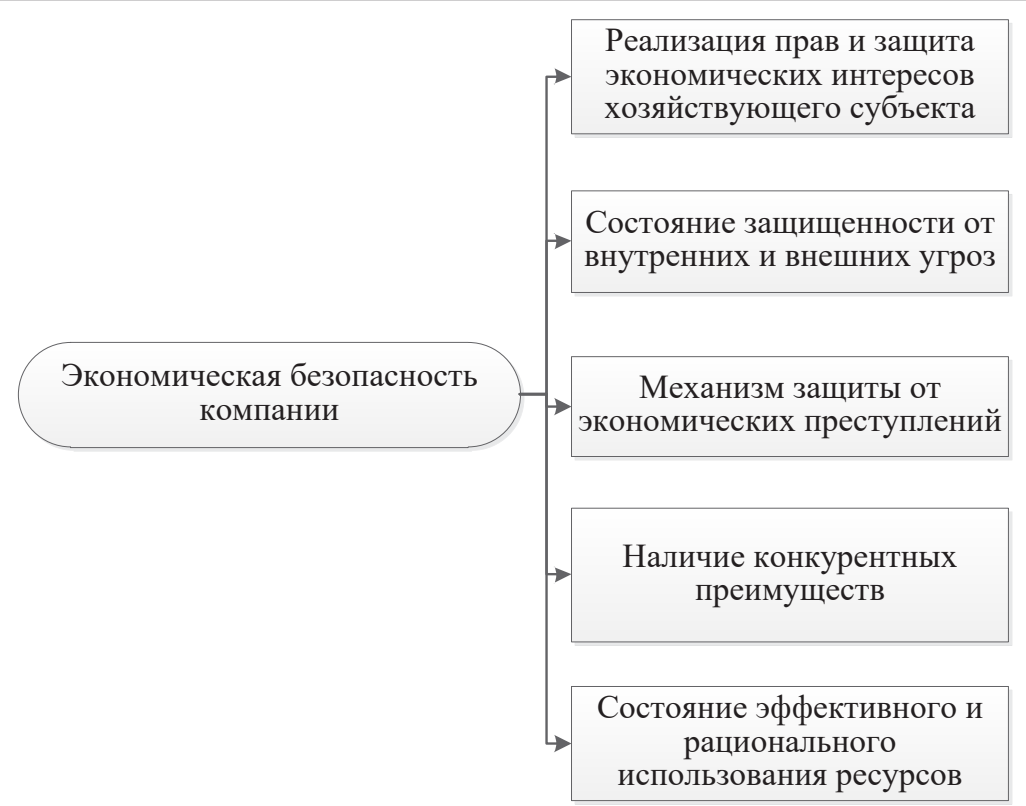

Рисунок 1. Сущность экономической безопасности хозяйствующего субъекта

Цели политики экономической безопасности компании
Пресечение коррупции и неэтического поведения персонала путем совершенствования внутренних регламентов и этических кодексов

Обеспечение высокой финансовой эффективности работы компании и ее финансовой устойчивости и независимости

Обеспечение технологической независимости компании и достижение высокой конкурентоспособности ее технологического потенциала

Обеспечение высокого уровня квалификации персонала компании и его интеллектуального потенциала

Обеспечение качественной правовой защищенности всех аспектов деятельности компании

Обеспечение защиты информационной среды компании, коммерческой тайны и защиты организации в целом

Обеспечение высокой эффективности менеджмента

Снижение рисков или их полное исключение за счет эффективной системы управления рисками

Рисунок 2. Цели политики экономической безопасности компании 
можностей, направленных на устойчивый рост и развитие в соответствующей (профильной) сфере деятельности $[1,4,9,12]$.

Исследуя существующие подходы к определению самого понятия «политика экономической безопасности» можно отметить, что в современной литературе представлено достаточно большое количество определений, однако большинство авторов / исследователей придерживаются подхода, что указанное понятие есть прямое сложение двух общепринятых терминов, а именно «политика» и «экономическая безопасность». При этом ключевым является термин «политика», который интерпретируется по-разному, в частности возможные варианты представлены на рисунке 3.

На основе выполненного анализа можно сделать вывод, что политика экономической безопасности в рамках отдельно взятого пред- приятия подразумевает некую деятельность, связанную с организацией и рациональной мобилизацией ресурсов для достижения целей обеспечения его экономической безопасности $[6,8]$.

Необходимо отметить, что в специализированной литературе присутствуют авторы, которые пытаются выполнить прямую увязку терминов «политика» И «экономическая безопасность» (рисунок 4).

Важно отметить, что указанные авторы специализируются на вопросах формирования и развития именно политики экономической безопасности, выделяют указанный процесс в самостоятельную тематику с точки зрения развития методических аспектов экономической безопасности на микроуровне. В частности, Алпысбаев К.С имеет достаточно много публикаций на исследуемую тематику. При этом данный автор, как видно из рисунка 2, не дает точного

\begin{tabular}{|c|r|}
\hline Ж. Блондель \\
\hline Т. Парсонс
\end{tabular}$\rightarrow \begin{array}{r}\text { Политика - деятельность, посредством которой приходят к решениям, } \\
\text { осуществляемым в рамках общества и для него }\end{array}$

Рисунок 3. Возможные вариации интерпретации термина «политика»

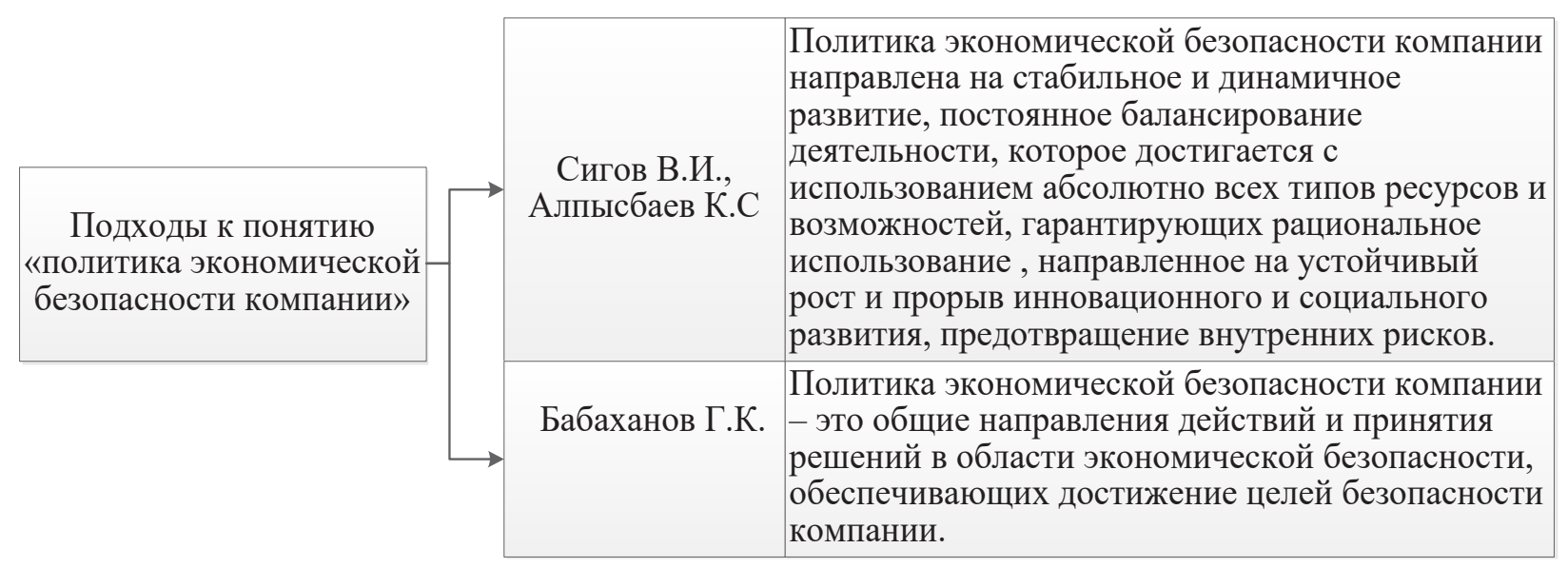

Рисунок 4. Варианты определение термина «политика экономической безопасности компании» как единого (целостного) понятия 
определения понятию «политика экономической безопасности», пытаясь сформировать понимание ее сущности через детальную (расширенную) характеристику данного термина. Указанный автор придерживается позиции, что эффективная политика экономической безопасности компании должна базироваться на определенных требованиях и условиях обеспечения экономической безопасности с точки зрения корпоративного управления. Следующий автор - Бабаханов Г.К. дает достаточно общее определение политики экономической безопасности, без подробного описания и уточнения отдельных характеристик, что затрудняет понимание смысла, вкладываемого в указанное понятие $[2,7,10]$.

Очевидно, что сущность политики экономической безопасности проявляется через функции, которые она реализует в системе управления современным предприятием. Обобщенно указанные функции представлены на рисунке 5.

Принципиальным в условиях реального функционирования системы экономической безопасности является решение ряда организационных вопросов, в частности утверждение состава отдела экономической безопасности и его места в организационной структуре компа- нии, определение его прав и полномочий, а также вариация действий в различных ситуациях во избежание личностных столкновений между подразделениями компании.

Следующим важным моментом в исследовании вопросов экономической безопасности является понятие ее эффективности. Ключевым условием эффективности политики экономической безопасности компании является осознание того факта, что она есть результат совместной деятельности сотрудников компании, способных проанализировать ее функции, цели и задачи на своем уровне и иметь возможность оказать непосредственное влияние на функционирование системы в целом [3, 11, 13]. Также эффективность политики во многом зависит от готовности персонала к выполнению соответствующего функционала при условии доведение до каждого сотрудника персональных обязанностей по поддержанию режима экономической безопасности.

Далее стоит отметить, что основные положения политики экономической безопасности должны быть отражены в соответствующих распорядительных документах, содержание которых определяется спецификой объекта.

Как правило, любая компания не обходит-

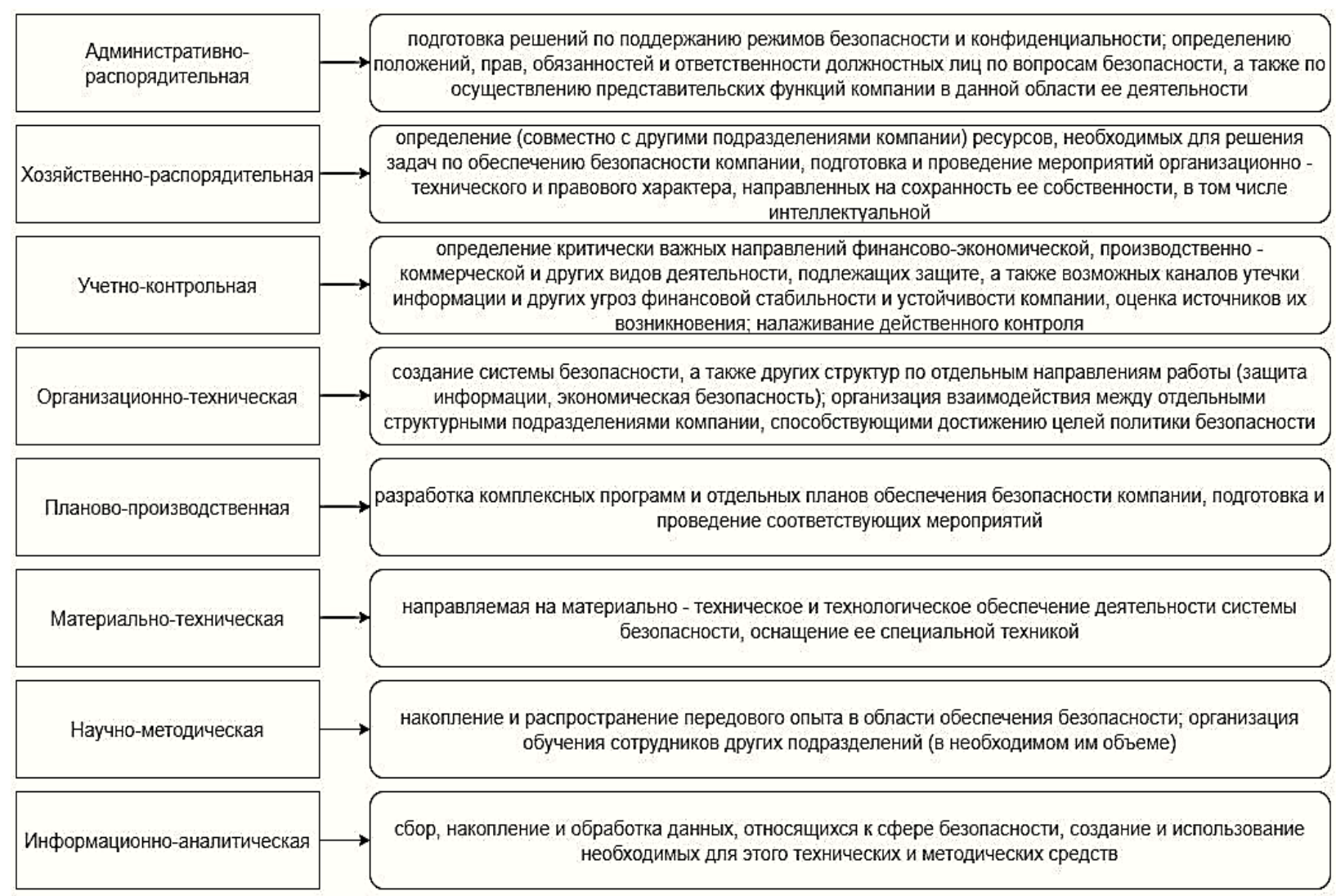

Рисунок 5. Основные функции политики экономической безопасности 
ся без Положений о коммерческой тайне, об информационной защите, об администраторе безопасности сети, Правил, разграничивающих доступ к информации, содержащейся в автоматизированных системах, правил допуска персонала и посетителей в помещения, где производится обработка конфиденциальных данных, а также порядка проведения служебного расследования по факту нарушения правил безопасности. Данная документация устанавливает ряд функций, необходимых для организации работы службы безопасности, контрольные, проверочные и иные функции, которые осуществляются ею в процессе деятельности.

Подводя итог проведенному в рамках настоящей статьи исследованию, можно сформулировать (определить) ряд требований к формированию эффективной и грамотной Политике экономической безопасности на уровне отдельно взятого предприятия. Рассмотрим каждое из них более детально:

1. Необходимо конкретизировать и четко обозначить основную цель экономической безопасности, которая, как правило, предполагает обеспечение должного уровня экономической безопасности хозяйствующего субъекта.

2. В рамках компании должны быть созданы на постоянной основе каналы сбора информации. Таким образом, действенность системы экономической безопасности организации основывается на качественных и достаточных для принятия решений информационных потоках: о самой организации, а также об основных ее видах деятельности; секторе рынка, в которой действует рассматриваемая компания; об экономическом состоянии государства в целом и т.д.

3. Обеспечить гибкость и своевременную адаптацию системы экономической безопасности. Поскольку организация - динамическая, постоянно изменяющееся система, наряду с из- менениями внешней и внутренней среды корпоративной структуры необходима адекватная корректировка (регулировка) системы экономической безопасности компании под происходящие изменения как внутри организации, так и за ее пределами.

4. В целях обеспечения должного уровня экономической безопасности необходимо разграничить элементы управления и обязанности уполномоченных лиц. Закрепление определенных обязанностей и целей за определенными лицами компании позволяет избежать дублирования функций, повышает уровень ответственности, а также уменьшает риск сговоров и иных корпоративных правонарушений.

5. Внедрение системы экономической безопасности должно иметь положительный экономический эффект, а именно результативность системы должна обеспечивать покрытие всех расходов на ее функционирование и содержание.

6. Система экономической безопасности копании должна соответствовать нормативноправовой базе государства.

Таким образом, под политикой экономической безопасности целесообразно понимать совокупность взглядов и мер, направленных на обеспечение экономической безопасности компании, создающая благоприятную среду для развития, достижения целей, поддержания должного уровня конкурентоспособности, а также выполнения долгосрочных планов компании. В свою очередь формирование и реализация политики экономической безопасности компании осуществляется посредством создания эффективной системы экономической безопасности в сфере взаимодействия финансовых, экономических, нормативно-правовых и иных элементов. В совокупности данные элементы отражают динамику роста и устойчивого развития компании.

\section{Библиографический список}

1. ичигин О. Э., Родионов Д. Г. Институциональный аспект формирования стратегических ориентиров государственной энергетической политики на региональном уровне при реализации стратегии национальной экономической безопасности // Экономика и предпринимательство. 2017. № 10-2. С. 394-399.

2. Алпысбаев К. С. Экономическая безопасность: значение и ее устойчивость //Kant. - 2018. - № . 1 (26).

3. Замбржицкая Е.С., Кошелева А. Ю. Оценка рисков как элемент СВК в страховых компаниях (на примере департамента андеррайтинга) // Актуальные проблемы современной науки, техники и образования. 2016. Т. 2. С. $116-119$.

4. Иванов Ф. К., Феофилова Т. Ю. Национальная система ПОД/ФТ: учебное пособие. - 2019. 
5. Касперович С. А., Дербинская Е. А. Экономическая безопасность предприятия: сущность, цели и направления обеспечения //Труды БГТУ. Серия 5: Экономика и управление. - 2016. - № 7 (189).

6. Родионов Д. Г., Зайцев А.А., Дмитриев Н.Д. Интеллектуальный капитал в стратегии обеспечения экономической безопасности Российской Федерации // Вестник Алтайской академии экономики и права. 2020. № 10-2. С. 156-166.

7. Сигов В.И., Алпысбаев К.С. Политика экономической безопасности в корпоративном управлении // Известия СПбГЭУ. 2018. № 6 (114).

8. Уразгалиев, В.Ш. Экономическая безопасность: учебник и практикум для вузов / В.Ш.Уразгалиев.-2-е изд., перераб. и доп.-Москва: Издательство Юрайт, 2020.- 725 с.

9. Усольцева И. В., Агаркова Е. С. К вопросу об обеспечении экономической безопасности организации //Молодой ученый. - 2017.- № . 37.- С. 67-69.

10. Феофилова Т.Ю. Проблемы теории экономической безопасности //Проблемы современной экономики.2009. - № . 4 .

11. Феофилова Т. Ю., Оганян М.А. Внутренний контроль в системе обеспечения экономической безопасности организации: создание и совершенствование //Аудит и финансовый анализ. - 2016. - № . 1.- С. $157-161$.

12. Харламов А.В. Экономическая безопасность в условиях четвертой промышленной революции //Архитектура университетского образования: построение единого пространства знаний.-2020.- С. 264-269.

13. Харламов А.В. Трансформация хозяйственной системы и обеспечение экономической безопасности //Петербургский экономический журнал. - 2020.- № . 3. 